\title{
Investigation on Mechanical, Thermal and Water Absorption Properties of Banana/Coir Reinforced Polypropylene Hybrid Composites
}

\author{
Bujjibabu Gunturu $^{1 *}$, Chittaranjandas Vemulapalli ${ }^{2}$, Ramakrishna Malkapuram ${ }^{3}$, Nagarjuna Konduru ${ }^{1}$ \\ ${ }^{1}$ Department of Mechanical Engineering, Malineni Perumallu Educational Society’s Group of Institutions, Guntur 522017, \\ Andhra Pradesh, India \\ ${ }^{2}$ Department of Mechanical Engineering, RVR \& JC College of Engineering, Guntur 522017, Andhra Pradesh, India \\ ${ }^{3}$ Department of Mechanical Engineering, Vignan's Foundation for Science Technology and Research University, Guntur \\ 522213, Andhra Pradesh, India
}

Corresponding Author Email: hodme@mpesguntur.com

https://doi.org/10.18280/rcma.303-402

Received: 25 November 2019

Accepted: 3 April 2020

\section{Keywords:}

banana fiber, coir fiber, FTIR, mechanical properties, polypropylene, thermogravimetry, $X R D$

\begin{abstract}
This study explores the merits of B/C fibers reinforced polypropylene to developed high mechanical performance, cost effective and light weight hybrid composite. B/C fibers reinforced polypropylene hybrid composites were prepared with different proportions. Variation in Banana, Coir and B/C fibers in hybrid composites, reveal the tensile, flexural, impact strength and water absorption. The PP and Banana, Coir fibers reinforced Composites were prepared by the twin screw extrusion of PP $80 \%$ with B-20, C-20 and $\mathrm{B} / \mathrm{C} 15 / 5,10 / 10$ and $5 / 15 \mathrm{wt} \%$. After extrusion, the extraction strands cut into pallets and injection molded machine make the test specimens. It was found that maximum tensile strength, the flexural strength and the impact strength at $20 \%$ of banana fiber. Tensile, flexural and impact strengths marginally have been decreased when decrease the banana fiber in the $\mathrm{B} / \mathrm{C}$ fiber reinforced polypropylene hybrid composites. Also observed water absorption of same composites for $24 \mathrm{hrs}$., $48 \mathrm{hrs}$. and $72 \mathrm{hrs}$. Thermogravimetry analysis (TGA), fourier transform infrared spectroscopy (FTIR) and XRD (X ray diffraction) was examined.
\end{abstract}

\section{INTRODUCTION}

The natural fiber reinforcement of thermoplastics composites has been the most research and development in the entire world. Because of as concern environmental changes; natural fibers are quick replacing synthetic fibers as reinforcing agents in thermosets and thermoplastics matrices; for example, natural fibers reinforced polypropylene composites now being commercialized in the various fields like automotive industries, sports goods, and decorative items. Composites cannot be recycled and reused; hence the usage of biodegradable natural fiber reinforced polypropylene composite will reduce the harmful effect of plastics waste on the environment, human beings, and animals. In recent years, natural fibers have attracted due to their potential applications in biomedical, bio engineering and environmental fields. Most of the fibers have low density, specific strength and modulus and surface that are easily modified [1,2]. Cellulose fibers have extreme advantages over the inorganic fibers like Strength, High specific stiffness, Availability, Light weight, Renewability, Non-hazardousness, Non-abrasiveness that reduces wear in processing equipment [3, 4].Natural fiber polymer based composites have been developed, using the thermoset matrix such as epoxy and polyester or using thermoplastic such as polypropylene. However, the use of polypropylene matrix increased the interest it is low cost, low processing temperature and recycled. Compared to natural fibers, kenaf fiber has superior toughness, high aspect ratio and it is currently increasing higher concentration to become the top most national product crop under the control of the Malaysian National Kenaf and Tobacco Board. Natural fiberbased polymer composites can develop positive mechanical properties such as strength, stiffness, and energy absorption [5]. In olden days the synthetic fibers such as glass fiber, carbon fiber and aramid fiber have been used as reinforcements. as concern manufacturing process, cost of fibers and difficult to be recycled and certain things represented by the surroundings and resource conservation, recently environmentally friendly products such as natural fiber, reusable material, biodegradable have been innovated. Sometimes lingo- cellulose fibers are low density and equivalent stiffness to the glass fiber. That is the reason; the natural fibers have been a growing interest as reinforcing fiber in polymeric composites [6, 7]. Few years ago, Thermoplastics and thermosets plastics have gain enormous magnification in the automobile industry. Because of environmentally friendliness, renewability of the fibers, good sound moderation capability. This type of composite materials has gain commercial success in the structural and semi structural applications. Best example for the interior components such as door trim panels from natural fiber polypropylene and exterior parts such as engines transmission covers from natural fiber polyster resins. Thermoplastic natural fiber composites have advantages over thermosets natural fiber composites such as suitable for injection molding and extrusion processing, recycling process, higher strength. Development of 
thermoplastic composites by using natural fibers benefited small amount of moisture resistance and corrosion resistance [8]. Recently, Incorporation of lingo cellulosic materials which are highly attentive, Used as reinforcing component in the thermoplastic composite, particularly price criteria and high-volume applications. Ligno cellulosic materials offer advantages over inorganic components such as greater deformability, less abrasive, low density and low cost per unit volume. Glass fiber is an inorganic fiber has high density and extensive and offering wide ranging excellent properties, particularly in ultimate strength of the composite. Main disadvantage of lingo cellulose fiber obstacle to be solved is the compatibility between reinforcement material and polymer matrix. Hydrophilic natures of lingo cellulosic material and hydrophobic of composites are the causes poor compatibility and interfacial properties $[9,10]$. Natural fiber reinforced composites have high strength and high modulus due to their chemical constituents. Banana and coir fibers increase the importance in composite materials; banana fiber has hemi cellulose and lignin. Lignin plays an important role as a binder for the cellulose fibers and behaves as an energy storage system. Coir is an abundant, versatile, renewable, cheap, and biodegradable lignocelluloses fiber used for making a wide variety of products. This paper presented mechanical properties of banana and coir fiber reinforced composite at $20 \%$ of weight fraction [11]. Banana fiber has good specific strength, high moisture uptake and low thermal conductivity. Many studies have been done on the development of new composite materials using banana fiber. This paper reported that mechanical properties banana and coir reinforced polymer composites with the fiber orientation and percentage of fiber [12]. Banana fiber has high cellulose content and low micro fibril angle imparts high mechanical properties. The banana fiber is composed of $56 \%$ cellulose, $17 \%$ lignin, $11 \%$ moisture, $7 \%$ extractives, \& 9\% ash. Many authors reported that mechanical properties of natural fibers reinforced hybrid composite varying the fiber percentage in composite [13-15]. Natural fiber reinforced polypropylene composites has been found rare combination of excellent mechanical, thermal, electrical, and chemical properties. Also, water absorption has been investigated of treated and untreated fibers reinforced polymer composites. In the untreated sample gained water more percentage than the treated samples [16].

Hence, in the current research work, banana and coir fibers taken as fillers and polypropylene as matrix material was developed hybrid composites by using twin screw extruder. Investigated the effect of fibers loading on the mechanical properties, thermal, moisture absorption and FTIR of the B/C fiber reinforced PP are also produced.

\section{MATERIALS AND METHODS}

\subsection{Materials}

The thermoplastic polymer polypropylene (PP) is used as matrix material (H110 MA) in the form of homopolymer pallets with density of $0.90 \mathrm{~g} / \mathrm{cc}$ and a melt flow index (MFI) $11 \mathrm{~g} / 10 \mathrm{~min}$ at $\left(230^{\circ} / 2.16 \mathrm{~kg}\right)$, collected from polypropylene company private limited. Polypropylene granules were white in color and granules melting temperature of PP $165^{\circ}-170^{\circ}$. Banana and Coir fibers used as reinforcing fibers and collected from rural area of east Godavari district, Andhra Pradesh, India. Banana fiber was extracted from banana stem and coir extracted from coconut bunch. After extraction of fibers waste material is removed from the fibers, then washed with water and exposed to sun and then dried for $24 \mathrm{hrs}$.

\subsection{Manufacturing of composites}

Hybrid composites of polypropylene matrix and different proportions of banana and coir fibers used as reinforcement were prepared by using twin screw extruder (Berstorff, Germany) with an L/D ratio of 33 with a temperature profile of $160,165,170,175,180,185$ and $190^{\circ} \mathrm{C}$. the extruded strands pelletized and stored in sealed packs containing desiccant. Five levels of filler loading (B:20\%, C:20\%, $\mathrm{B} / \mathrm{C}: 15 / 5,10 / 10$ and $5 / 15 \mathrm{wt} \%$ ) were selected in sample preparation by using injection moulding machine $(\mathrm{M} / \mathrm{s}$ ARBURG 500-210, Germany) as per ASTM test methods. Mechanical test specimens were manufactured by Injection moulding machine (M/s ARBURG 500-210, Germany) with 50 -ton capacity and operating pressure of $70-80 \mathrm{MP}$. Five specimens prepared in each $\mathrm{B} / \mathrm{C}$ natural fiber reinforced polypropylene (PP) hybrid composite. After sample preparation, the test samples conditioned at $23^{\circ} \mathrm{C}$ and $55 \% \mathrm{RH}$ for $24 \mathrm{hrs}$ as per ASTM D 618 before testing.

\subsection{Mechanical testing}

Instron testing machine (AUTOGRAPH AG IS 50KN) is used to test the Tensile and flexural strengths were carried out as per ASTM D 638 and ASTM D 790 respectively. Specifications of tensile test specimens are length $115 \mathrm{~mm} \mathrm{x}$ width $12.7 \mathrm{~mm}$ x thickness $3.2 \mathrm{~mm}$; flexural test specifications are $127 \times 12.7 \times 6.2 \mathrm{~mm}$. Izod impact tester (Ceast 645600) is used to tested the Izod impact strength were carried out as per ASTM D 256. Impact test specimen prepared with specifications of $50 \mathrm{~mm} \times 12.7 \mathrm{~mm} \times 3.2 \mathrm{~mm}$. In each composite were tested five specimens and taken average value of five tested specimens.

\subsection{Water absorption}

$6.2 \times 12.7 \times 127$ (thickness x width x length) dimension B/C fiber reinforced polypropylene hybrid composite specimens which are used to calculated the water absorption percentage as per ASTM D 570. The hybrid composite specimens heated in an electric oven at $50^{\circ} \mathrm{C}$ before moisture absorption test. For the water absorption test, specimens weight measured by A Denver Instron balance machine. The specimens are weighed before dipped into water, then immersed into water at ambient temperature. After immersion, the excess water on the surface of the specimens was removed using dry cloth. After remove moisture on the specimens, the final weight of the specimens was taken. The percentage of moisture absorption of $\mathrm{B} / \mathrm{C}$ reinforced polypropylene hybrid composite was determined as following equation.

(\%) moisture absorption

$$
=\frac{\text { wet weight }- \text { intial weight }}{\text { initial weight }}
$$

\subsection{Thermal properties}

Perkin Elmer (PYRIS) Diamond TGA/DTG thermal analyzer used to Thermogravimetry analysis was conducted on $\mathrm{B} / \mathrm{C}$ fiber reinforced polypropylene hybrid composites. TGA, 
DTG were carried out simultaneously by thermal analyzer and the data was processed and analyzed by PYRIS. Muse measure and standard analysis software. A compressed mass of substance of different composites were subjected to increase the temperature at rate of $20^{\circ} \mathrm{C} / \mathrm{min}$ in the temperature range from ambient to $600^{\circ} \mathrm{C}$ using $\mathrm{Al}_{2} \mathrm{O}_{3}$ as the reference material. Indium and gallium were used as standards for temperature calibration.

\subsection{FTIR}

It is a technique used to obtain an infrared spectrum of absorption or emission of a solid, liquid or gas. An FTIR spectrometer simultaneously collects high spectral resolution data over a wide spectral range. Organic, polymeric and in some cases, inorganic materials determined by the FTIR test. The FTIR test uses infrared light to scan specimens and observe chemical properties. This test measures the absorption of infrared radiation by the specimen material versus wave length. The infrared absorption bands identify molecular components and structures. FTIR is an effective analytical instrument for detecting functional groups and characterizing covalent bonding information. The FTIR spectra of the B/C fibers reinforced PP hybrid composite was recorded in an FTIR (attenuated total reflection) bomem spectrometer.

\subsection{XRD (X-ray diffraction)}

D8 advance Goniometer model 2036E201, (Bruker) using $\mathrm{Cu} \mathrm{K} \alpha$ radiation $(\mathrm{K} \alpha=1.54056)$ at an accelerating voltage of $40 \mathrm{kV}$ and a current of $15 \mathrm{~mA}$ instrument used to measure the $\mathrm{X}$-ray differection. The diffraction intensity was measured in a $2 \Theta$ range of $5^{\circ}-80^{\circ}$. B/C fibers reinforced polypropylene hybrid composite samples were subjected to crystalline analysis.

\section{RESULT AND DISCUSSION}

\subsection{Tensile properties}

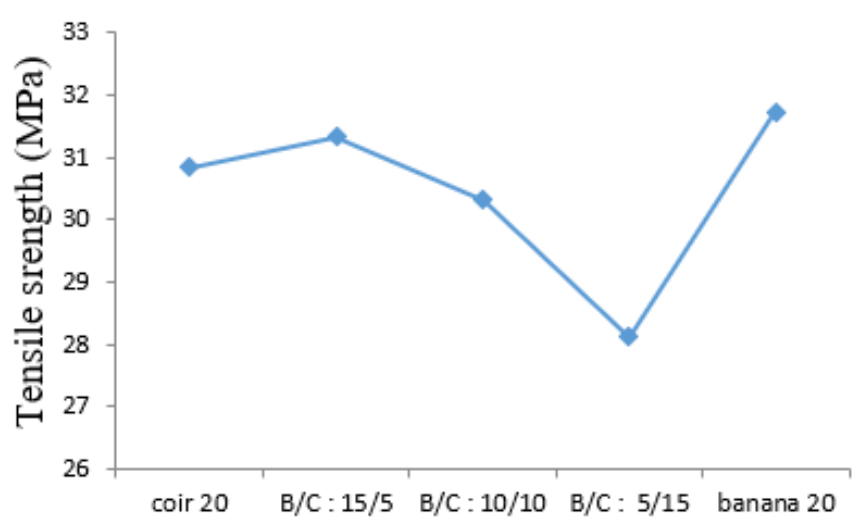

\section{Percentage of fiber(wt \%)}

Figure 1. Comparison of tensile strength of composites atdifferent fiber loadings

The Comparison of strength performance on Banana fiber, Coir fiber and $\mathrm{B} / \mathrm{C}$ fiber reinforced polypropylene hybrid composites is shown in Figure 1. Clearly, Banana fiber reinforced polypropylene composite exhibited optimum tensile strength compared to coir fiber and B/C fiber reinforced polypropylene hybrid composites. Minimum tensile strength has been found at $\mathrm{B} / \mathrm{C}: 5 / 15$ fibers reinforced hybrid composite. Banana fiber has low lignin content as compared to coir fiber; lignin content fibers produces poor the mechanical properties.

\subsection{Flexural properties}

The Figure 2 shows the flexural strengths of different composites of banana $20 \%$, coir $20 \%$ and $\mathrm{B} / \mathrm{C}$ fibers $15 / 5$, $10 / 10$ and $5 / 15 \%$ reinforced polypropylene hybrid composite. Maximum flexural strength has been developed at $20 \%$ of banana fiber represented in Figure 2. Least flexural strength produced at $\mathrm{B} / \mathrm{C}$ : $5 / 15$ fibers reinforced polypropylene hybrid composite. It is observed that, when increasing the coir fiber in the hybrid composites, the flexural strength was decreased. According to the above graph, banana fiber reinforced composite has more flexural strength then the coir fiber reinforced composite. The presence of lignin content in the coir fiber, decreases the flexural properties of coir fiber reinforced polymer composites. The properties of lignin content are brittle and have generated low strength in the composite materials.

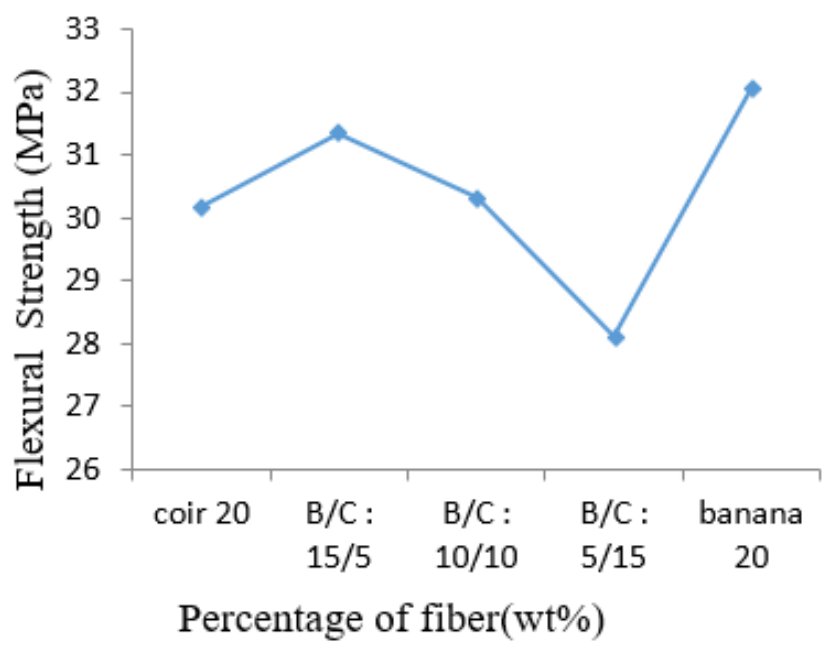

Figure 2. Comparison of flexural strength of composites at different fiber loadings

\subsection{Impact strength}

Impact strength $20 \%$ of fiber loading reinforced polypropylene hybrid composites as shown in Figure 3. Impact strength of the fibers reinforced polymer composites depends on the nature of the filler, polymer and bonding strength between fiber/matrix, the development and configuration of the composite and at the time of test conditions. Figure 3 found that the Maximum impact strength have been produced at $20 \%$ banana fiber reinforced polypropylene composite. Impact strength of all the fiber reinforced polymer composites followed same trend as in case of tensile strength and flexural strength. Least value exhibited $45.6 \mathrm{~J} / \mathrm{m}$ at $\mathrm{B} / \mathrm{C}: 5 / 15$ fibers reinforced polypropylene hybrid composite due to brittle nature of the coir fiber and has low strength as compared to banana fiber. Tensile, flexural and impact strengths at different compositions are mentioned in the Table 1. 
Table 1. Mechanical properties of B/C reinforced polypropylene hybrid composites

\begin{tabular}{cccc}
\hline Banana/ Coir fibers & Tensile strength (MPa) & Flexural strength (MPa) & Impact strength (J/m) \\
\hline B/C: $15 / 5$ & 31.3316 & 31.9529 & 50.6 \\
B/C:10/10 & 30.3062 & 30.224 & 47.5 \\
B/C:5/15 & 28.1197 & 27.5043 & 45.6 \\
B:20 & 31.73095 & 32.0372 & 62.06 \\
C: 20 & 30.8372 & 30.1765 & 49.84 \\
\hline
\end{tabular}

Table 2. Percentage of water absorption of B/C fiber reinforced polypropylene hybrid composite

\begin{tabular}{cccc}
\hline Fiber Percentage (\%) & 24 hours & 48 hours & 72 hours \\
\hline B/C $: 15 / 5$ & 0.656935 & 1.1489217 & 1.25833142 \\
B/C $: 10 / 10$ & 0.88577305 & 1.163825 & 1.33087764 \\
B/C $: 5 / 15$ & 0.9459399 & 1.2784734 & 1.33335814 \\
B: 20 & 0.987925357 & 1.0976948 & 1.207464325 \\
C: 20 & 0.78387458 & 1.567749 & 1.56774916 \\
\hline
\end{tabular}

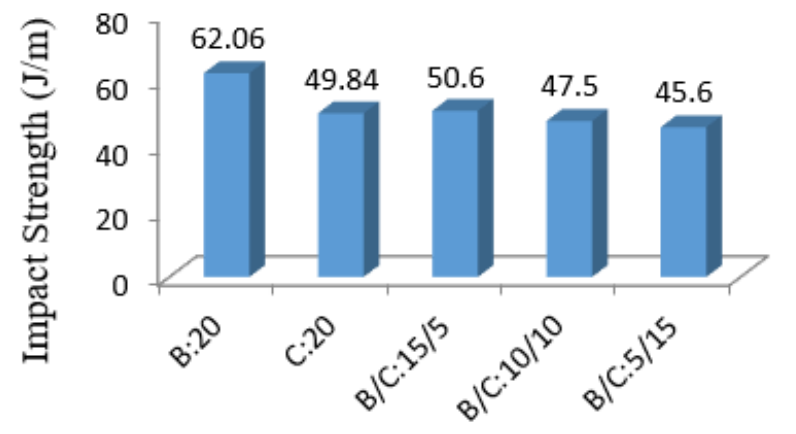

Percentage of fiber (wt\%)

Figure 3. Comparison of impact strength at different fiber loadings

\subsection{Water absorption}

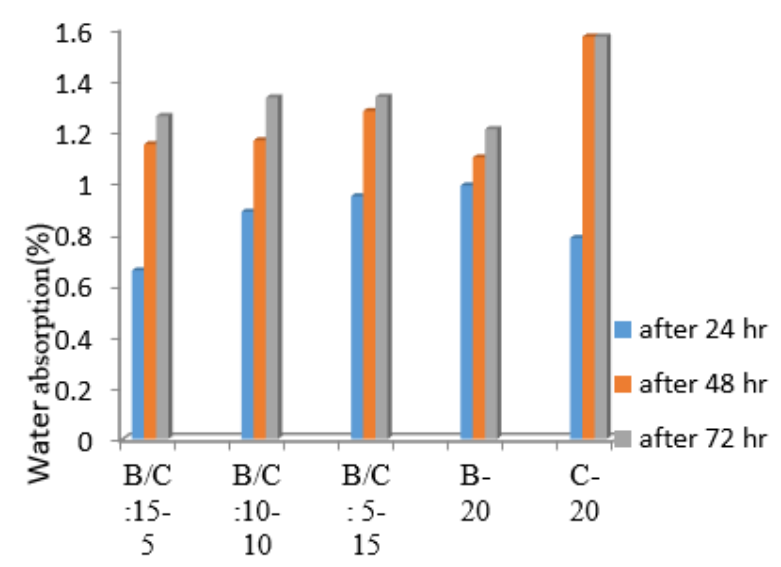

Fiber loading (wt $\%$ )

Figure 4. Percentage of water absorption at different fiber loadings

Water absorption of B:20, C:20, B/C:15/5,10/10 and 5/15 fibers reinforced polymer hybrid composites at different fiber loadings are shown in Figure 4. Five different composites have been selected for the water absorption test and tested water absorption for 24 hrs., 48 hrs. and 72 hrs. From Figure 4 observed the water absorption percentage increased while increasing the coir percentage in the hybrid composites, and same trend followed for the $48 \mathrm{hrs}$. and $72 \mathrm{hrs}$. also compared to banana fiber and hybrid composites, coir fiber reinforced polypropylene composite absorbed more water percentage. as mentioned earlier, the hydroxyl groups in coir fiber are responsible for absorbed more moisture percentage. While increasing the coir fiber in the hybrid composite, the number of hydroxyl groups increased in the composite, which in turn increased the moisture absorption. Water absorption percentage of different composites are shown in the Table 2.

\subsection{TGA \&DTG}

The TGA and DTG curves of B/C fiber reinforced polypropylene hybrid composites at $15 / 5,10 / 10$ and $5 / 15$ are expressed in the Figures 5,6 and 7. TGA thermograms which measures the weight loss of various hybrid composites with increasing the temperature shown in figures. The Figure 5 shows result of TGA and DTG thermograms of B/C fiber reinforced polypropylene hybrid composites. From the Figure 7 weight loss started at $25^{\circ} \mathrm{C}$ temperature then gradually decreased its weight of composite up to $300^{\circ} \mathrm{C}$. Between $25^{\circ} \mathrm{C}$ to $300^{\circ} \mathrm{C}$ temperature, weight loss of composite only $9.2 \%$, A distinct weight loss appeared between $300^{\circ} \mathrm{C}$ to $425^{\circ} \mathrm{C}$. DTG thermograms displayed in the same graph, it shows the absorbing moisture percentage of hybrid composite with respect to the temperature. DTG curve shows very small moisture percentage vaporized between $200^{\circ}$ to $300^{\circ}, 300^{\circ}$ to $430^{\circ}$ attributed sudden loss of weight duo to evaporation of moisture content.

The Figure 6 shows the decomposition of hybrid composite material started at $250^{\circ} \mathrm{C}$, between $250^{\circ} \mathrm{C}$ and $450^{\circ} \mathrm{C}$ moisture absorbed only $10.30 \%$. Drastically weight loss of hybrid composite between $350^{\circ} \mathrm{C}$ to $475^{\circ} \mathrm{C}$ is $84.4 \%$. the total amount weight loss of composite is $94.70 \%$ at $540^{\circ} \mathrm{C}$ temperature. DTG thermograms shows the two levels of moisture absorbed, one is gradually decreased its moisture content in the composites between the temperature 250 to 4000 . In the second level, Decomposition of composites between the temperature of $400^{\circ} \mathrm{C}$ to $500^{\circ} \mathrm{C}$.

From the Figure 7 observed that the composite which is increasing its weight loss with increasing the temperature. $16.76 \%$ weight loss of composite upto $350^{\circ} \mathrm{C}$ temperature, then it is abruptly changing its weight loss between the $350^{\circ}$ to $475^{\circ} \mathrm{C}$ temperature.

\subsection{FTIR}

Figure 8, 9 and 10 shows almost similar ranges of the FTIR spectroscopic analysis of $\mathrm{B} / \mathrm{C}$ fibers reinforced polypropylene 
hybrid composites. The IR spectrum of $\mathrm{B} / \mathrm{C}$ fiber clearly shows the presence of the characteristic band of the $\mathrm{N}=\mathrm{O}$ group in the region of $1300-1400 \mathrm{~cm}^{-1}$. An absorption band of C-O stretched at the region of $1300-1000 \mathrm{~cm}^{-1}$. This absorption band may be due to the carboxyl group of acetyl ester in cellulose and carboxyl aldehyde in lignin. Functional groups of $\mathrm{B} / \mathrm{C}$ fibers reinforced polypropylene hybrid composites are shown in Table 3.

Table 3. Functional groups of hybrid composites

\begin{tabular}{ccc}
\hline Functional group names & Absorption Ranges $\left(\mathbf{c m}^{-\mathbf{1}}\right)$ & Type of Vibration \\
\hline Alkanes: $\mathrm{CH}_{3}$ & $3000-2800$ & H-C-H Asymmetric \& Symmetric Stretch \\
Amines-Secondary: R-NH & $1550-1450$ & N-H Bend \\
Nitro Groups: $\mathrm{NO}_{2}$ & $1400-1300$ & N=O Bend \\
Esters:c-ch & $1300-1000$ & (C-O Stretch) \\
\hline
\end{tabular}

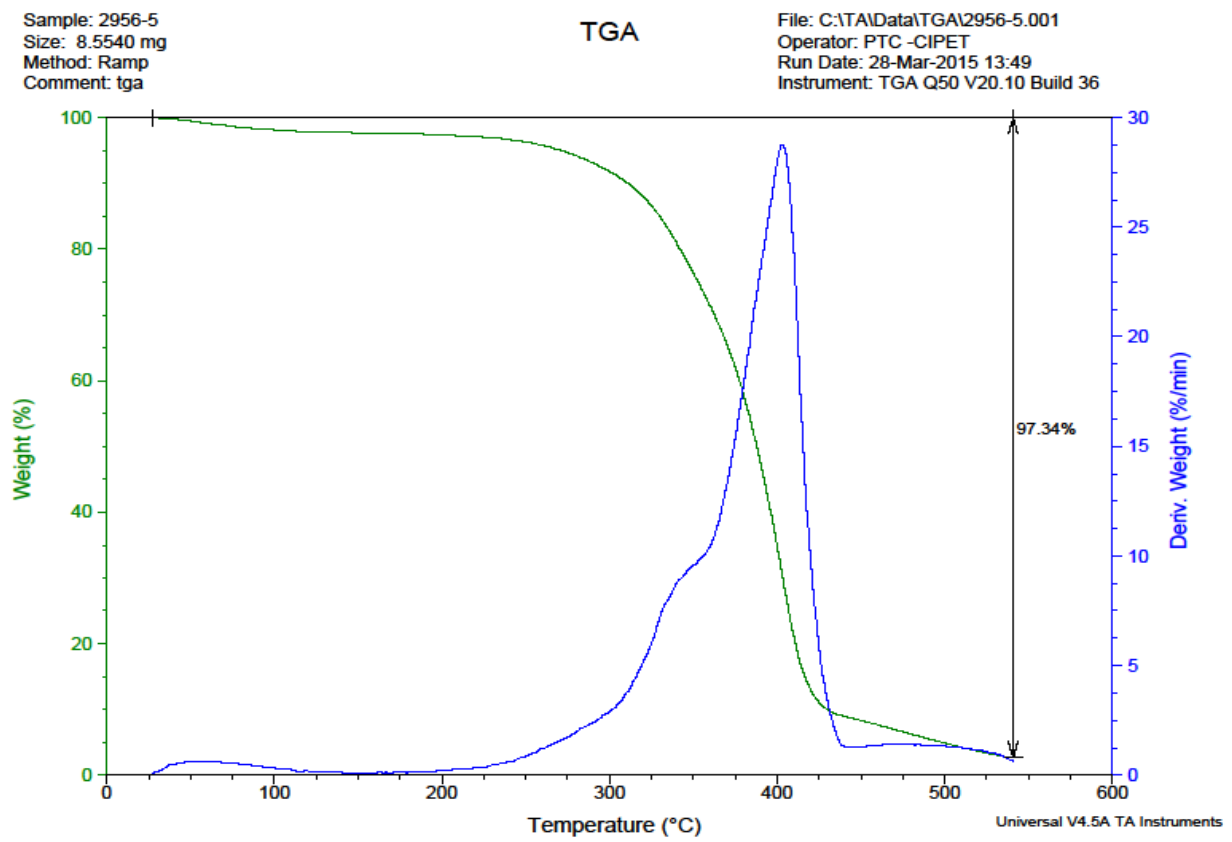

Figure 5. TGA \& DTG thermograms of B/C 15/5 (wt \%) reinforced polypropylene hybrid composite

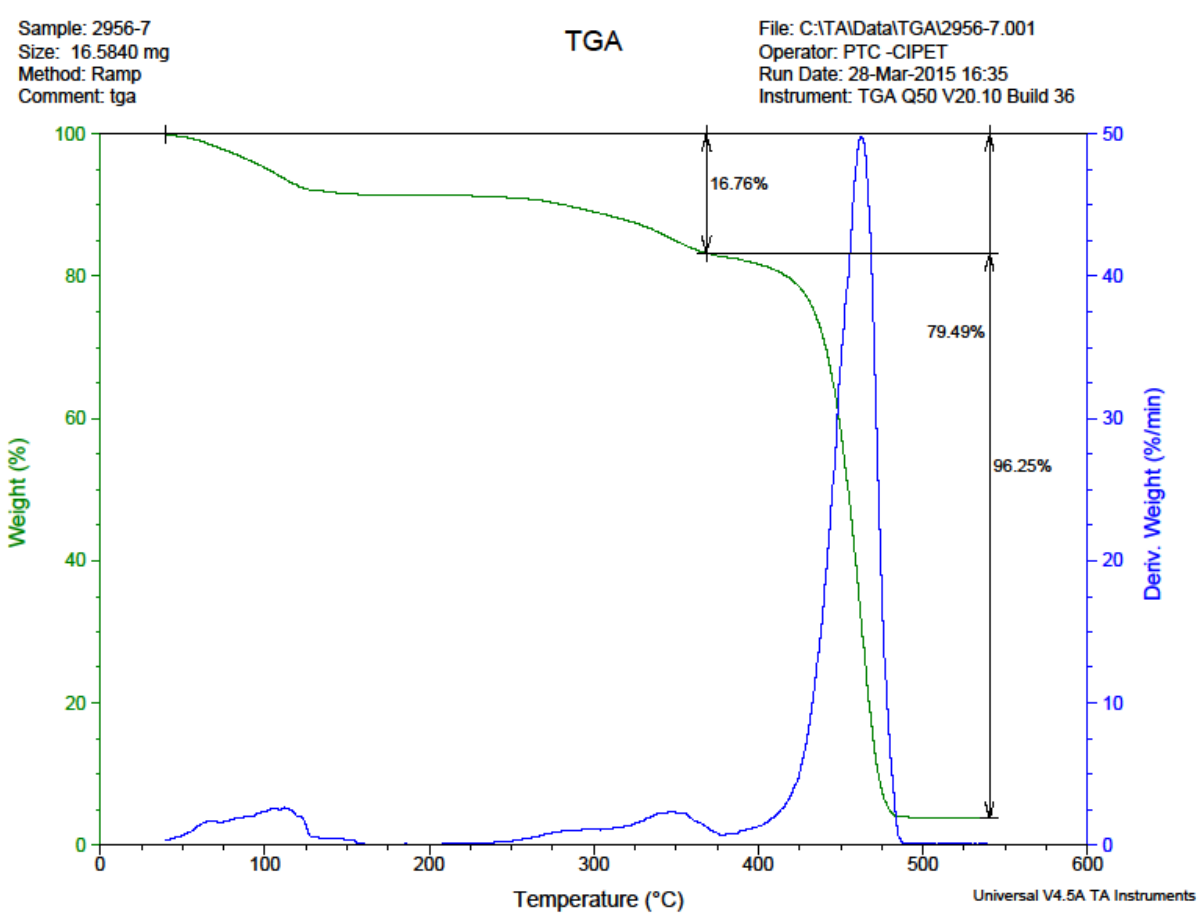

Figure 6. TGA \& DTG thermograms of B/C 10/10 (wt\%) reinforced polypropylene hybrid composite 


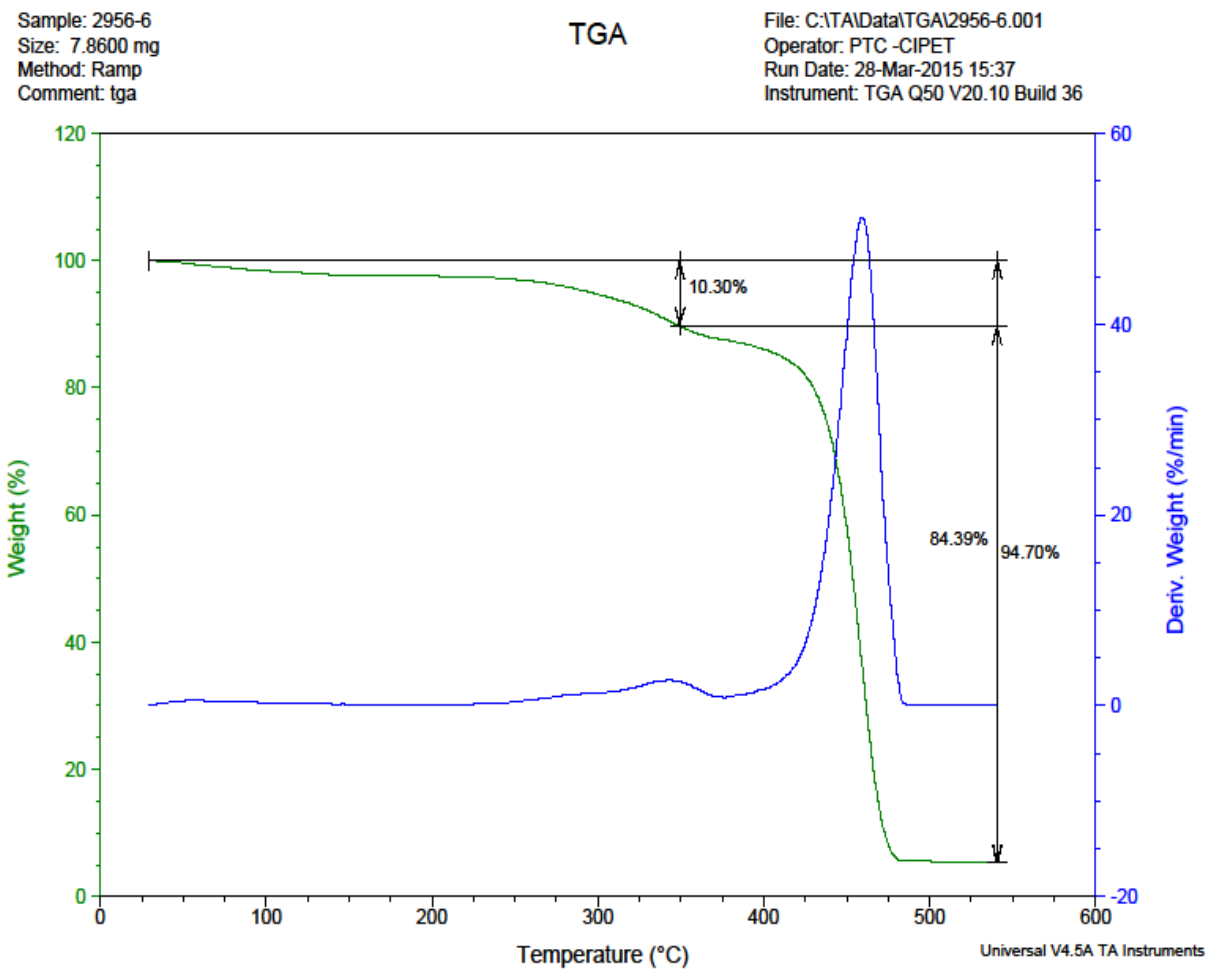

Figure 7. TGA \& DTG thermograms of B/C 5/15 (wt\%) reinforced polypropylene hybrid composite

\section{Agilent Resolutions Pro}

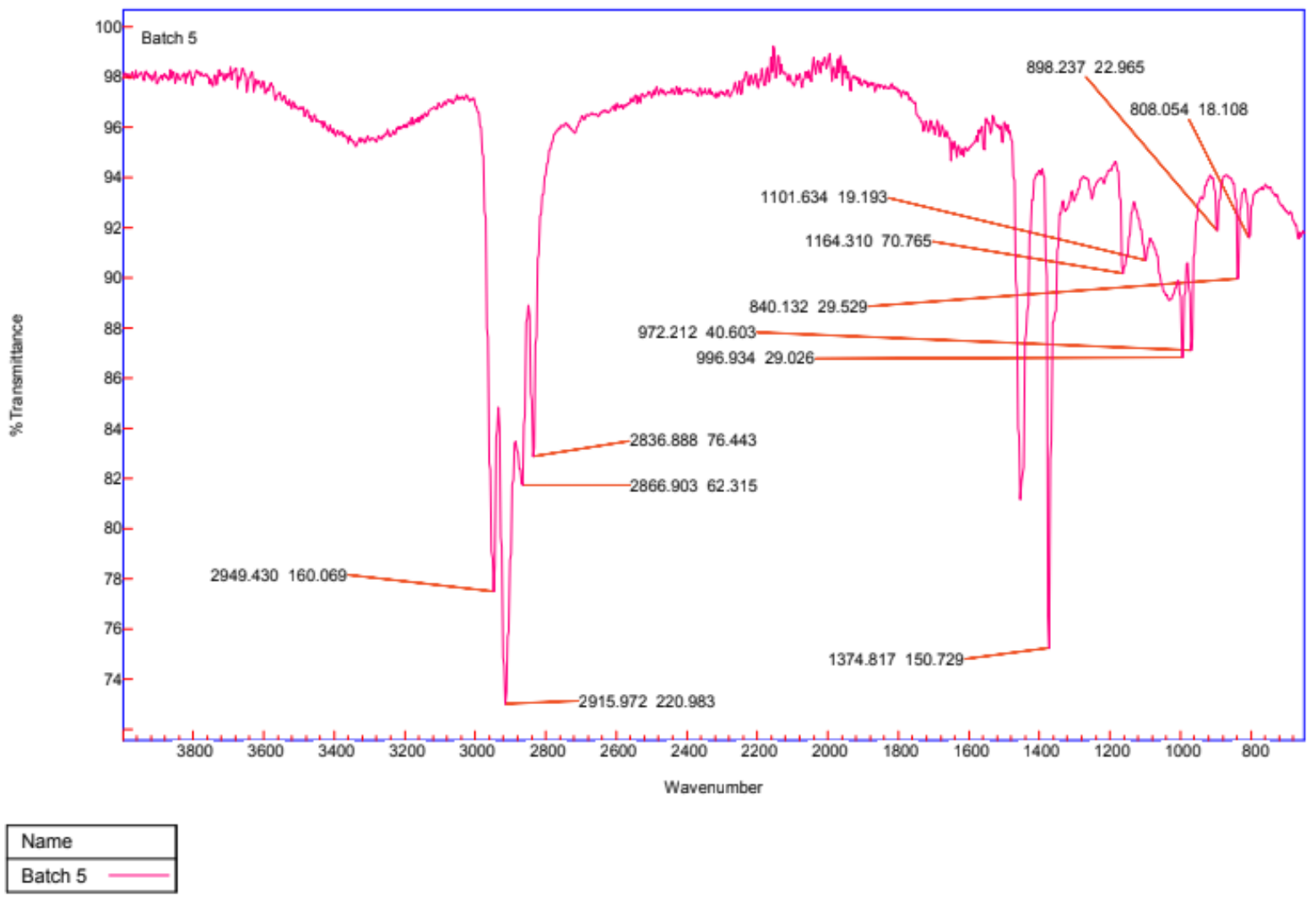

Figure 8. FTIR B/C :15/5 \% fiber reinforced polypropylenehybrid composite 


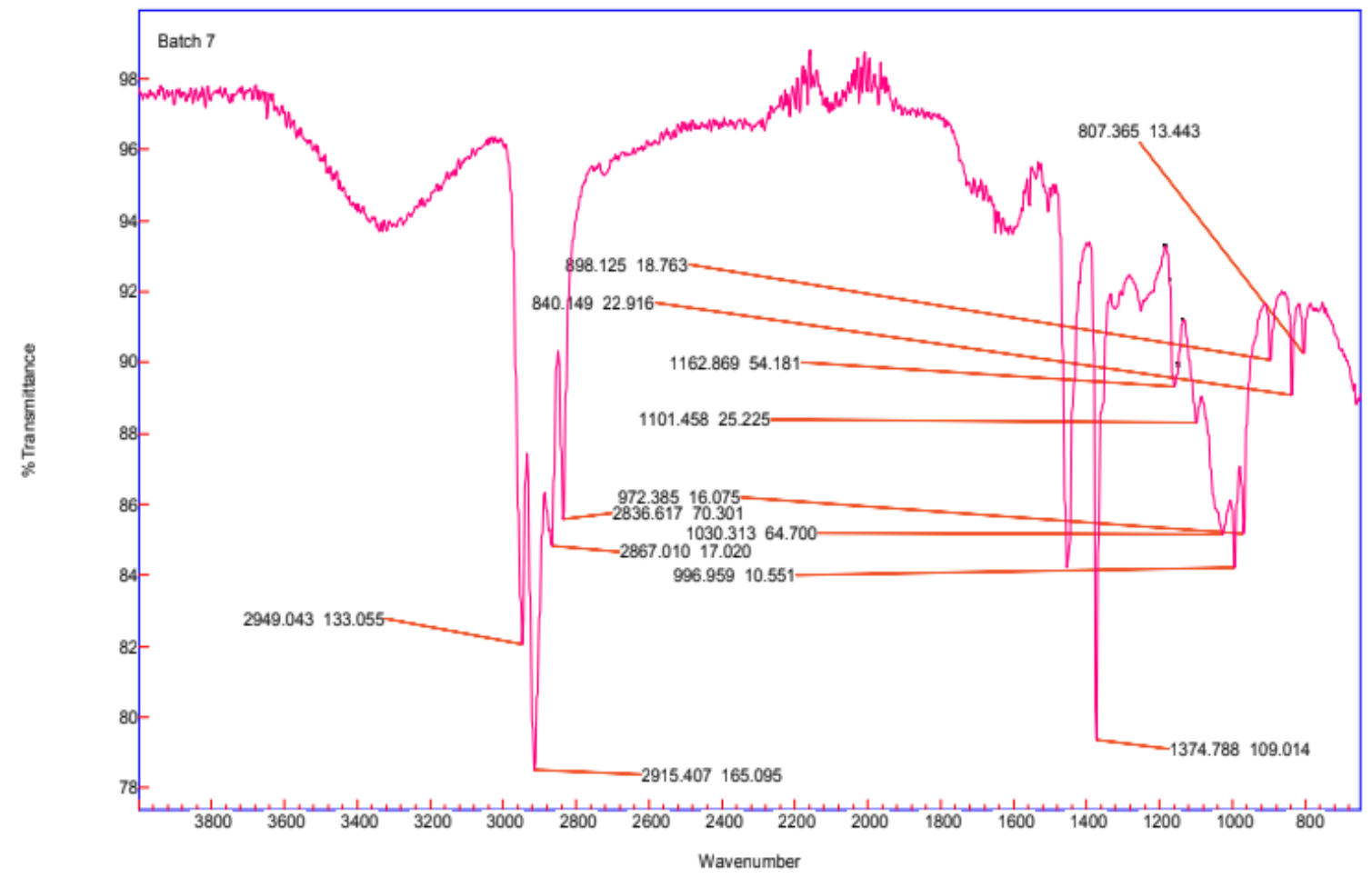

\begin{tabular}{|l|}
\hline Name \\
\hline Batch 7 \\
\hline
\end{tabular}

Figure 9. FTIR B/C :10/10 \% fiber reinforced polypropylene hybrid composite

\section{Agilent Resolutions Pro}

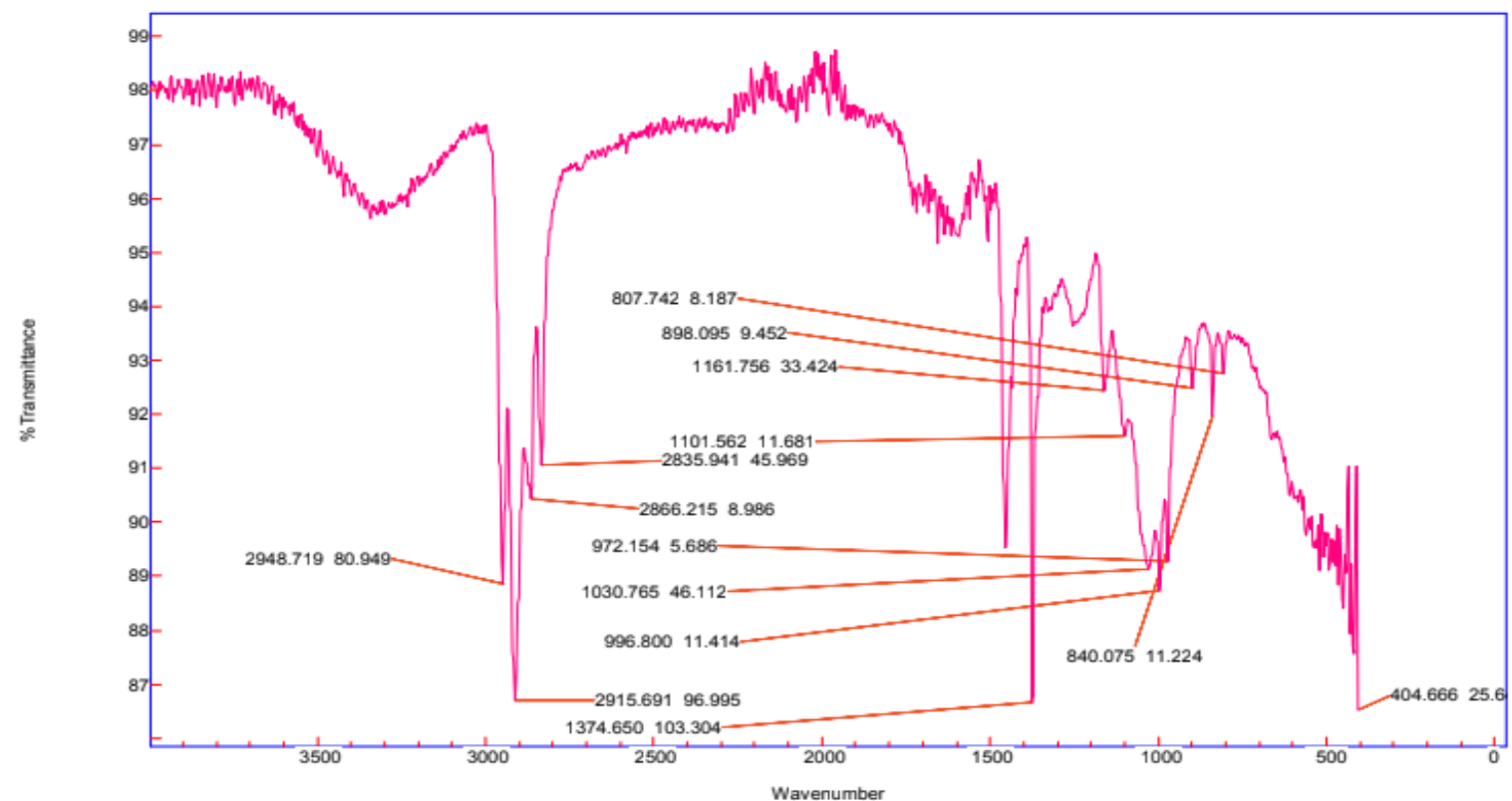

\begin{tabular}{|l|}
\hline Name \\
\hline Batch 6 \\
\hline
\end{tabular}

Figure 10. FTIR B/C :5/15 \% fiber reinforced polypropylene hybrid composite

\subsection{XRD analysis}

XRD analysis of $\mathrm{B} / \mathrm{C}$ fibers reinforced polypropylene hybrid composites as shown in Figure 11, 12, 13. The X-ray defraction pattern in Figure 11 shows that the intensity peak at
(22 degrees and1221counts) and in Figure 13 shows that the intensity peak at ( 16 degrees and 1302 counts). This indicates that banana stem fiber contains both amorphous/disordered regions. Hence Figure 13 B/C: 5/15 shows that more intensity than that of Figure $11 \mathrm{~B} / \mathrm{C}: 15 / 5$. 


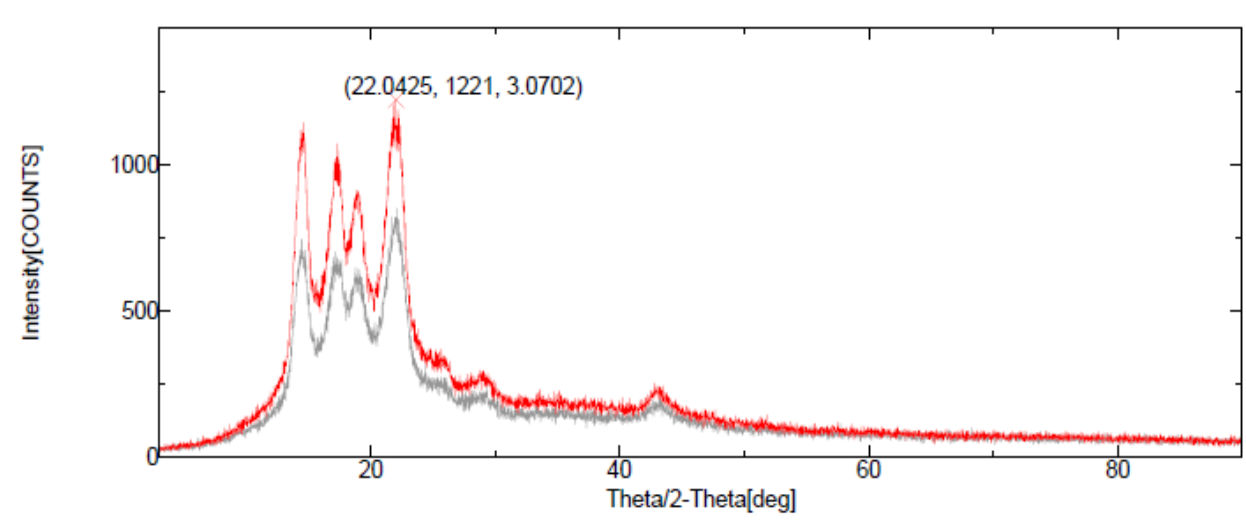

Figure 11. Intensity Count at B/C: $15 / 5$ fiber reinforced polypropylene hybrid composite

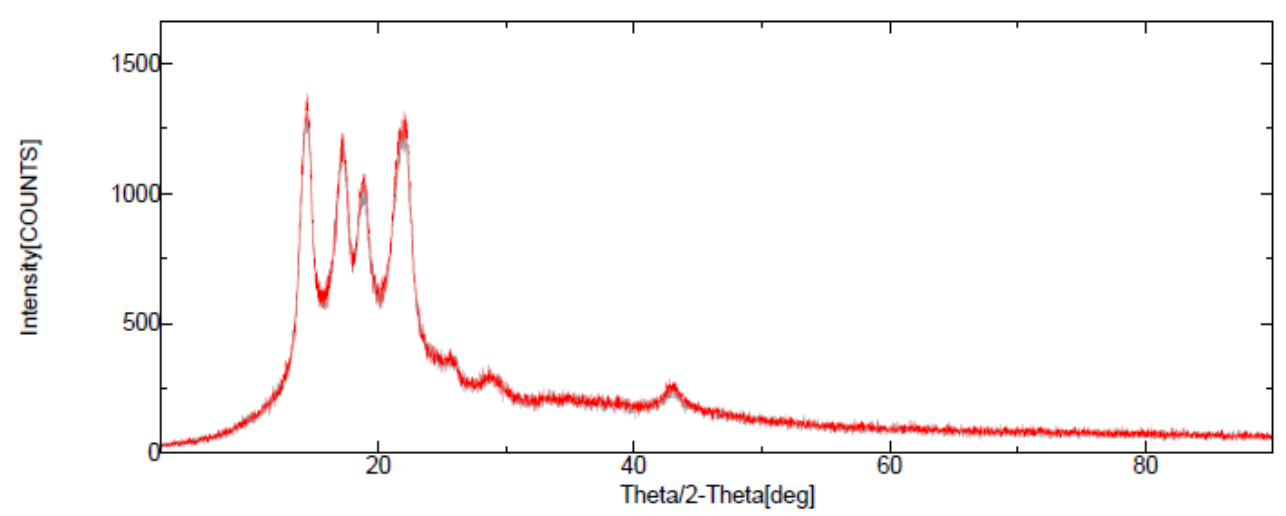

Figure 12. intensity count at B/C: 10/10 fiber reinforced polypropylene hybrid composite

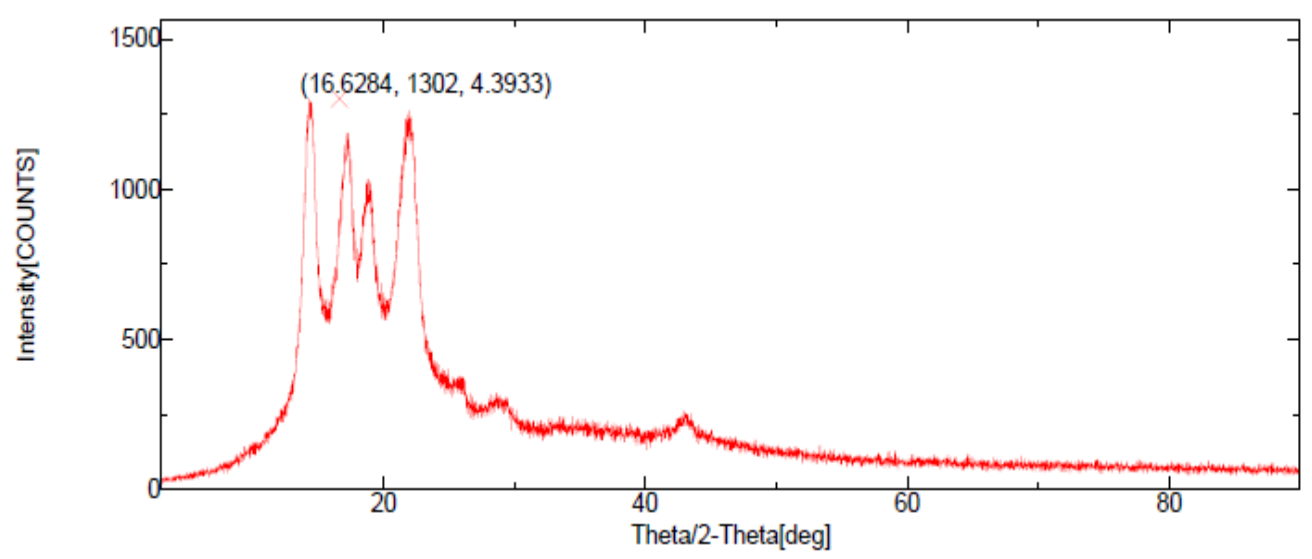

Figure 13. intensity count at B/C: 5/15 fiber reinforced polypropylene hybrid composite

\section{CONCLUSION}

In the current work, Banana fiber, Coir fiber and $\mathrm{B} / \mathrm{C}$ fibers reinforced polypropylene composites were prepared using twin screw extruder and injection molding method. A significant effect on the Banana, Coir and $\mathrm{B} / \mathrm{C}$ fibers reinforced PP hybrid composites observed the mechanical properties, thermal properties, and micro structural analysis. The following conclusions can be drawn from the experimental results of this study.

Mechanical properties of B/C fibers reinforced PP hybrid composites are mainly depended on the fiber aspect ratio, fiber orientation, and the distribution of fibers. Exhibited maximum tensile strength at $20 \%$ of banana fiber and minimum tensile strength was recorded at 5\% of banana and $15 \%$ of coir fibers.
Although the mechanical properties of hybrid composites affected by banana and coir fibers incorporated into polypropylene matrix, the characteristics of the higher strength banana fiber such as fiber orientation and fiber length are the major factor that are controlled mechanical properties of hybrid composite. However, the increase in mechanical properties of hybrid composites was depended on the percentage of banana fiber. In addition, that the poor orientation of coir fiber and lignin percentage is more in the coir fiber leads to the reduction in mechanical properties of hybrid composite. Flexural strength of Banana, Coir and B/C Fibers reinforced polypropylene composites followed same trend as in the tensile strength. Due to the lignin content in the coir fiber gain more water absorption in the coir fiber reinforced polypropylene composites as compared to Banana 
and $\mathrm{B} / \mathrm{C}$ fibers reinforced polypropylene composites. TGA graphs showed maximum thermal stability at $\mathrm{B} / \mathrm{C}$ : $5 / 15$ reinforced polypropylene hybrid composites.

\section{REFERENCES}

[1] Uawongsuwan, P., Yang, Y.Q., Hamada, H. (2014). Long jute fiber - reinforced polypropylene composite: Effects of jute fiber bundle and glass fiber hybridization. Journal of Applied Polymer Science, 132(15): 1-10. https://doi.org/10.1002/app.41819

[2] Tran, N.H., Ogihara, S., Kobayashi, S. (2011). Mechanical properties of short coir/pbs biodegradable composites: Effect of alkali treatment and fiber content. $18^{\text {th }}$ International Conference on Composite Materials, Jeju, Korea.

[3] Muensri, M., Kunanopparat, T., Menut, P., Siriwattanayotin, S. (2011). Effect of lignin removal on the properties of coconut coir fiber/wheat gluten biocomposite. Composites Part A: Applied Science and Manufacturing, $\quad$ 42(2): 173-179. https://doi.org/10.1016/j.compositesa.2010.11.002

[4] Islam, N., Rahman, R., Haque, M. (2010). Psysicomechanical properties of chemically treated coir reinforced polypropylene composites. Composites: Part A, 41(2): 192-198 https://doi.org/10.1016/j.compositesa.2009.10.006

[5] Mansor, M.R., Sapuan, S.M., Zainudin, E.S. (2013). Stiffness prediction of hybrid kenaf/glass fiber reinforced polypropylene composites using rule of mixtures (ROM) and rule of hybrid mixtures (RoHM). Journal of Polymer Materials, 30(3): 321-334 https://www.researchgate.net/publication/259357890

[6] Yang, Y.Q., Ota, T., Morii, T., Hamada, H. (2011). Mechanical property and hydrothermal aging of injection molded jute/polypropylene composites. Journal of Material Science, 46(8): 2678-2684. https://doi.org/10.1007/s10853-010-5134-8

[7] Mittal, M., Chaudhary, R. (2018). Development of PALF/glass and COIR/glass fiber reinforced hybrid epoxy composites. Journal of Materials Science \& Surface Engineering, 6(5): 851-861. https://doi.org/10.jmsse/2348-8956/6-5.1
[8] Pantha, S., Sain, M. (2007). Injection - molded short hemp fiber /glass fiber reinforced polypropylene hybrid composites - mechanical, water absorption and thermal properties. Journal of Applied Polymer Science, 103(4): 2432-2441. https://doi.org/10.1002/app.25486

[9] Rozman, H.D., Zuliahani, A., Tay, G.S. (2010). Effects of rice husk $(\mathrm{RH})$ particle size, glass fiber (GF) length, $\mathrm{RH} / \mathrm{GF}$ ratio, and addition of coupling agent on the mechanical and physical properties of polypropyleneRH-GF hybrid composites. Journal of Applied Polymer Science, $\quad$ 115(6): 3456-3462. https://doi.org/10.1002/app.30719

[10] Sarkhel, G., Choudhury, A. (2012). Preparation and characterization of chemically modified jute-coir hybrid fiber reinforced epoxy novolac composites. Journal of Applied Polymer Science, 125(4): 3038-3049. https://doi.org/10.1002/app.36610

[11] Hariprasad, T., Dharmalingam, G., Raj, P. (2013). A study of mechanical properties of banana-coir hybrid composite using experimental and fem techniques. Journal of Mechanical Engineering and Sciences, 4: 518531. http://dx.doi.org/10.15282/jmes.4.2013.16.0049

[12] Devaraju, A. (2015). Influence of fiber percentage on mechanical properties of hybrid composite materials. Journal of Material Science and Mechanical Engineering, 2(13): 1-5.

[13] Mathew, T., Sajeevan, V.K., Pranav, A., Sathyan, N.R. (2017). Fabrication \&testing of banana-hair reinforced hybrid composite. International Journal of Engineering Science and Computing, 7(4): 6667-6670.

[14] Singh, V.K., Chauhan, S., Singh, B.D. (2012). Mechanical behavior of banana fiber based hybrid bio composites. Journal of Material Environmental Sciences, 3: 185-194.

[15] Patel, H., Parkhe, A., Shrama, P.K. (2013). Mechanical behaviors of banana and sisal hybrid composites reinforced with epoxy resin. International Journal of Research - Granthaalayah, 4(1): 206-216.

[16] Haydaruzzaman, Khan, A.H., Hossain, M.A., Khan, M.A., Khan, R.A. (2010). Mechanical properties of the coir fiber-reinforced polypropylene composites: Effect of the incorporation of jute fiber. Journal of Composite Materials, 44 : https://doi.org/10.1177\%2F0021998309344647 